Check for updates

Cite this: RSC Adv., 2017, 7, 32120

\title{
Photocatalytic degradation of imidazolium ionic liquids using dye sensitized $\mathrm{TiO}_{2} / \mathrm{SiO}_{2}$ composites $\uparrow$
}

Received 2nd May 2017

Accepted 12th June 2017

DOI: $10.1039 / \mathrm{c} 7 \mathrm{ra0} 4939 \mathrm{k}$

rsc.li/rsc-advances

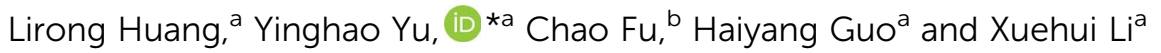

Ionic liquids (ILS) are widely applied in diverse fields, however, ILs bring considerable challenges to the ecosystem when exposed to the environment due to their cytotoxicity and high chemical stability. It is thus increasingly important to investigate measures for the degradation of IL wastes in industrial processes. This paper presents the preparation of dye-sensitized photocatalysts $\left(\mathrm{DCQ}-\mathrm{TiO}_{2} / \mathrm{SiO}_{2}\right)$ and their applications in the degradation of 4 imidazolium ILs (1-butyl-3-methylimidazolium bromide, [BMIM]Br; 1-butyl-3methylimidazolium tetrafluoroborate, $[\mathrm{BMIM}] \mathrm{BF}_{4} ;$ 1-butyl-3-methylimidazolium hexafluorophosphate, [BMIM]PF 6 ; 1-butyl-3-methylimidazolium bis(trifluoromethylsulfonyl)imide, [BMIM]NTf ${ }_{2}$ ). The photocatalysts are prepared through in situ incorporation of $\mathrm{TiO}_{2}$ into silica matrices and sensitization with 2,9dichloroquinacridone (DCQ). The photocatalysts are then characterized with $\mathrm{N}_{2}$ adsorption-desorption isotherm measurements, transmission electron microscopy (TEM), X-ray diffraction (XRD), Raman spectroscopy, Fourier transform infrared spectroscopy (FT-IR), elemental analysis and ultraviolet-visible diffuse reflectance spectroscopy (UV-vis DRS). The results show that these photocatalysts exhibit high catalytic activities when they are applied in the degradation of imidazolium ILs. The degradation efficiency for $[\mathrm{BM} I \mathrm{M}] \mathrm{Br}$ can reach up to $95 \%$ under simulated sunlight irradiation in 180 minutes. The photodegradation intermediates of $[\mathrm{BMIM}]^{+}$are identified as harmless and easily biodegradable moieties.

\section{Introduction}

In the past two decades, ionic liquids (ILs) have attracted considerable interest in the diverse fields of synthesis, catalysis, materials science, separation technology, ${ }^{1}$ and $\mathrm{CO}_{2}$ capture. ${ }^{2,3}$ The increasing research interest is due to the following unique physicochemical characteristics of ILs: tuneable structures and properties, negligible vapor pressure, excellent chemical and thermal stability ${ }^{4}$ as well as high polarity and ionic conductivity. ${ }^{5}$ However, the high thermal and chemical stability lead to the persistence and accumulation of ILs in the environment in the case of any industrial leakage. ${ }^{6,7}$ Meanwhile, there have been several reports discussing the toxicity of ILs to algae, bacteria, fungi, invertebrates, and vertebrates. ${ }^{8-12}$ Exposed ILs will thus be a challenge to terrestrial ecosystems. ${ }^{13}$ It is essential to investigate efficient and economic measures for the degradation of ILs.

A series of studies reported the mineralization of ILs with Fenton reagents, ${ }^{\mathbf{1 4 - 1 6}}$ UV radiation, ${ }^{17-19}$ sonication, ${ }^{20}$ and gamma irradiation $^{\mathbf{2 1 , 2 2}}$ as aids. The use of UV radiation showed good performance in the degradation of ILs. It is important to further

${ }^{a}$ School of Chemistry and Chemical Engineering, South China University of Technology, Guangzhou 510641, China. E-mail: ceyhyu@scut.edu.cn; Tel: +86 20 87114707

${ }^{b}$ SINTEF Energy Research, 7465 Trondheim, Norway

$\dagger$ Electronic supplementary information (ESI) available. See DOI: $10.1039 / \mathrm{c} 7 \mathrm{ra} 04939 \mathrm{k}$ evaluate the efficiency of UV usage, the catalytic activity and recyclability of $\mathrm{TiO}_{2} \cdot{ }^{20}$ Due to the high photocatalytic activity, nontoxicity and good chemical stability, $\mathrm{TiO}_{2}$ is regarded as an ideal and powerful photocatalyst. ${ }^{23}$ However, its band gap is as high as $3.2 \mathrm{eV}$ and it can only be excited by the UV light that makes up only $3-5 \%$ of the entire solar spectrum. ${ }^{24-26}$ In addition, there are also difficulties in practical applications of $\mathrm{TiO}_{2}$. Although the common form of ultrafine powder increases the surface area and the number of active sites, ${ }^{27}$ it is easy to be agglomerated into large particles in aqueous solutions. The photocatalytic performance is thus reduced. ${ }^{28}$

To solve the aforementioned problem, several studies have been performed to support $\mathrm{TiO}_{2}$ onto a wide variety of materials such as zeolites, ${ }^{27,28}$ glass beads ${ }^{29}$ and glass capillaries ${ }^{30}$ for the photocatalytic degradation of methylene blue, methyl orange and agri-food industry effluents. In this study, a series of $\mathrm{TiO}_{2} /$ $\mathrm{SiO}_{2}$ are in situ synthesized and then sensitized with 2,9dichloroquinacridone (DCQ) in order to show better photocatalytic abilities upon full solar spectrum irradiation. The dyesensitized photocatalysts (DCQ- $\left.-\mathrm{TiO}_{2} / \mathrm{SiO}_{2}\right)$ are characterized through BET, TEM, XRD, Raman, FT-IR, elemental analysis and UV-vis DRS, and are then used in the degradation of some imidazolium ionic liquids. Experimental results show that the dye sensitization of titania-silica materials with DCQ can significantly increase the photodegradation efficiency. More than $95 \%$ of $[\mathrm{BMIM}] \mathrm{Br}$ can be degraded within $180 \mathrm{~min}$ under simulated sunlight irradiation. The photodegradation 
intermediates of [BMIM $]^{+}$are identified as 2-oxo-2-ureidoacetic acid, butyric acid and others. These intermediates are harmless and can be easily biodegraded in the ecosystem.

\section{Experimental}

\subsection{Synthesis of the photocatalysts}

In this study, $\mathrm{TiO}_{2} / \mathrm{SiO}_{2}$ composite materials were prepared according to the method reported in literature. ${ }^{31,32}$ Triblock copolymer P123 $\left(\mathrm{EO}_{20} \mathrm{PO}_{70} \mathrm{EO}_{20}, M_{\mathrm{w}}=5800\right.$, Sigma-Aldrich) was used as the structure-directing agent, tetramethoxysilane (TMOS, Acros) and tetrabutyl orthotitanate (TBOT, Acros) were used as the silica source and titania source, respectively. All reagents were used as received. The catalysts obtained are denoted as $X \% \mathrm{TiO}_{2} / \mathrm{SiO}_{2}(X=0,10,20,30,40)$, where $X$ stands for the mass ratio of $\mathrm{Ti}$ in the whole synthesis gel $(X=0$, the catalyst obtained is SBA-15). In a typical synthesis of $30 \% \mathrm{TiO}_{2} /$ $\mathrm{SiO}_{2}, 8.0 \mathrm{~g}$ of P123 was dissolved in $160 \mathrm{~mL}$ of $1 \mathrm{~mol} \mathrm{~L}^{-1} \mathrm{HCl}$ solution under magnetic stirring at room temperature. Subsequently, $9.2 \mathrm{~g}$ of TMOS and $6.6 \mathrm{~g}$ of TBOT were added to the solution. The resulting mixture was stirred for $24 \mathrm{~h}$ at $40{ }^{\circ} \mathrm{C}$. Hydrothermal crystallization was then performed in a Teflonlined autoclave for $24 \mathrm{~h}$ at $110{ }^{\circ} \mathrm{C}$. The white product was separated using vacuum filtration and was then washed with $1 \mathrm{~mol} \mathrm{~L}^{-1} \mathrm{HCl}(25 \mathrm{~mL} \times 3)$. The solid obtained was dried for $10 \mathrm{~h}$ at $100{ }^{\circ} \mathrm{C}$ and subsequently calcined for $5 \mathrm{~h}$ at $550{ }^{\circ} \mathrm{C}$ to remove the template. The dye-sensitized photocatalyst DCQ$30 \% \mathrm{TiO}_{2} / \mathrm{SiO}_{2}$ was prepared in the following way: $2.0 \mathrm{~g}$ of $30 \%$ $\mathrm{TiO}_{2} / \mathrm{SiO}_{2}$ was dispersed in $100 \mathrm{~mL}$ of acidic methanol solution $(\mathrm{pH}=4.7)$ under vigorous stirring for $15 \mathrm{~min} .40 \mathrm{~mL}$ methanol solution of $0.01 \mathrm{~mol} \mathrm{~L}^{-1}$ DCQ (Gaoyou Auxiliary Factory) was then added. The mixture was stirred for $24 \mathrm{~h}$ at room temperature. After the reaction, the precipitate was separated using vacuum filtration and was washed with methanol $(60 \mathrm{~mL} \times 3)$. The solid obtained was then dried for $10 \mathrm{~h}$ at $100{ }^{\circ} \mathrm{C}$ in vacuum.

\subsection{Characterization of the photocatalysts}

The textural properties of the photocatalysts were determined by $\mathrm{N}_{2}$ adsorption-desorption isotherms at $-196{ }^{\circ} \mathrm{C}$ using a Micromeritics ASAP-2010. Prior to adsorption, the samples were thoroughly degassed at $150{ }^{\circ} \mathrm{C}$ for $8 \mathrm{~h}$ under vacuum to remove water and other physically adsorbed species. The specific surface area $\left(S_{\mathrm{BET}}\right)$ was calculated through the standard Brunauer-Emmett-Teller (BET) method. TEM images were captured on a JEM-2100 microscope (JEOL) operated at $200 \mathrm{kV}$. XRD patterns of the samples were obtained on a $\mathrm{D} / \max -3 \mathrm{~A}$ diffractometer (Rigaku) equipped with a $\mathrm{CuK}_{\alpha} \mathrm{X}$-ray source (40 $\mathrm{kV}, 30 \mathrm{~mA}, \lambda=0.154 \mathrm{~nm}$ ) and Ni filter. Diffractograms were recorded in the $2 \theta$ ranges of $0.6-10^{\circ}$ (small angle) and $10-80^{\circ}$ (wide angle) at a scanning step of $0.02^{\circ}$. Raman spectroscopy was carried out on a LabRamHR spectrometer (Horiba Jobin Yvoc Inc.). All experiments were performed on the electrode surface by using a $632.8 \mathrm{~nm}$ excitation line from an internal HeNe laser with a power of $6 \mathrm{~mW}$. FT-IR spectra were recorded on an Equinox-55 spectrophotometer (Bruker) by $\mathrm{KBr}$ wafer technique. Elemental analysis was performed on a Vario EL III
(Elementar). UV-vis DRS were obtained in the wavelength of 200-800 nm by a UV-vis spectrophotometer (Shimadzu U-3010) equipped with an integrating sphere assembly and $\mathrm{BaSO}_{4}$ was used as a reflectance standard.

\subsection{Test of photocatalytic activity}

The photocatalytic degradation of ionic liquids was conducted using $X \% \mathrm{TiO}_{2} / \mathrm{SiO}_{2}$ and DCQ- $X \% \mathrm{TiO}_{2} / \mathrm{SiO}_{2}$ as photocatalysts under simulated sunlight irradiation provided by a $300 \mathrm{~W}$ Xe lamp (CEL-HXUV300, Beijing Au light company). A quartz reactor with cooling jacket was used to keep the temperature controlled at $25{ }^{\circ} \mathrm{C}$. In each experiment, $0.2 \mathrm{~g}$ of photocatalyst was ultrasonically dispersed in a $100 \mathrm{~mL}$ of solution, where the concentrations of ionic liquids and $\mathrm{H}_{2} \mathrm{O}_{2}$ were $45 \mathrm{mg} \mathrm{L}^{-1}$ and $14 \mathrm{mg} \mathrm{L}^{-1}$ respectively, and $\mathrm{pH}$ was adjusted to 3.9. The suspension was magnetically stirred at $200 \mathrm{rpm}$ and then stored in dark for $30 \mathrm{~min}$ to reach adsorption-desorption equilibrium. $1 \mathrm{~mL}$ of sample was then taken out as a blank control to eliminate the effects of adsorption. During the degradation process, $1 \mathrm{~mL}$ of sample was collected by a pipette at $30 \mathrm{~min}$ intervals and then filtered through a $0.45 \mu \mathrm{m}$ cellulose membrane (Millex, Millipore). The degradation degree of ionic liquids was measured by high-performance liquid chromatography (HPLC, Agilent 1200) equipped with a reverse-phase C18 analytical column (Zorbax SB-C18). A water-acetonitrile mixture $(70: 30$, $\mathrm{v} / \mathrm{v}$ ) was used as the mobile phase. The flow rate was set to be 1 $\mathrm{mL} \mathrm{min}^{-1}$. The degradation efficiency $(D \%)$ was then calculated according to eqn (1):

$$
D^{\%}=\left(C_{0}-C_{t}\right) / C_{0} \times 100
$$

where $C_{0}$ is the initial concentration of ionic liquids, and $C_{t}$ is the concentration of ionic liquids after irradiation for a selected time interval. To identify intermediates in the photocatalytic degradation of ionic liquids (mainly the cation of [BMIM] $]^{+}$), liquid chromatography-mass spectrometry (LC/MS) was performed on an Agilent 1100/Esquire HCT PLUS equipped with an electrospray ionization source.

\section{Results and discussion}

\section{1 $\mathrm{N}_{2}$ adsorption-desorption isotherms}

The textural properties of SBA-15, $X \% \mathrm{TiO}_{2} / \mathrm{SiO}_{2}$, and DCQ- $X \%$ $\mathrm{TiO}_{2} / \mathrm{SiO}_{2}$ samples were investigated and shown in Fig. 1. All samples display type IV isotherms and hysteresis loops in the relative pressure range of $0.5<P / P_{0}<0.9$. These features are associated with capillary condensation of $\mathrm{N}_{2}$ in primary mesopores, ${ }^{28}$ which therefore indicate that the samples are mesoporous materials. Hysteresis loops of $X \% \mathrm{TiO}_{2} / \mathrm{SiO}_{2}$ and DCQ$X \% \mathrm{TiO}_{2} / \mathrm{SiO}_{2}$ show reduced sharpness and are shifted to lower relative pressures $\left(P / P_{0}\right)$ over a larger range of $P / P_{0}$ with the incorporation of $\mathrm{TiO}_{2}$ and DCQ in the matrix of $\mathrm{SiO}_{2}$, indicating that pores in these samples are less uniform and smaller. ${ }^{32-34}$ Detailed information on $S_{\mathrm{BET}}$, average pore diameter $\left(D_{\mathrm{BJH}}\right)$, and pore volume $\left(V_{\text {pore }}\right)$ is given in Table $\mathrm{S} 1$ (ESI $\dagger$ ). It shows that higher $\mathrm{TiO}_{2}$ loadings in the samples result in the decrease of $S_{\mathrm{BET}}$. Further, $S_{\mathrm{BET}}$ of DCQ- $X \% \mathrm{TiO}_{2} / \mathrm{SiO}_{2}$ are smaller than that 


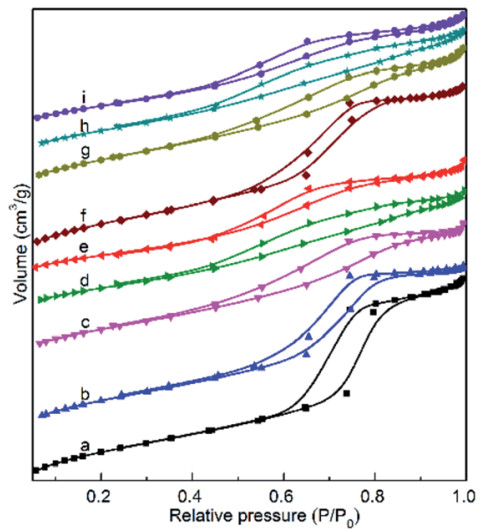

Fig. $1 \mathrm{~N}_{2}$ adsorption-desorption isotherms of the samples: (a) SBA15; (b)-(e) 10, 20, 30, 40\% $\mathrm{TiO}_{2} / \mathrm{SiO}_{2}$ (f) -(i) DCQ-10, 20, 30, 40\% TiO 2 $\mathrm{SiO}_{2}$.

of their counterpart $\left(X \% \mathrm{TiO}_{2} / \mathrm{SiO}_{2}\right)$ due to the introduction of DCQ. Nonetheless, the $S_{\mathrm{BET}}$ values of all materials remain high $\left(836.9-496.6 \mathrm{~m}^{2} \mathrm{~g}^{-1}\right)$.

\subsection{XRD analysis}

Small-angle XRD patterns of SBA-15, $X \% \mathrm{TiO}_{2} / \mathrm{SiO}_{2}$, and DCQ$X \% \mathrm{TiO}_{2} / \mathrm{SiO}_{2}$ samples are shown in Fig. 2A. SBA-15 produces three reflections of (1 000$),\left(\begin{array}{lll}1 & 1 & 0\end{array}\right)$, and (2 $\left.\begin{array}{lll}2 & 0\end{array}\right)$, which correspond to a two-dimensional hexagonal meso-structure of the $p 6 \mathrm{~mm}$ space group with high structural periodicity. ${ }^{35,36}$ The samples of $10 \% \mathrm{TiO}_{2} / \mathrm{SiO}_{2}$ and DCQ-10\% $\mathrm{TiO}_{2} / \mathrm{SiO}_{2}$ produce XRD patterns similar to that of SBA-15, indicating that they retain the SBA-15 structure. However, the diffraction intensities of the $\left(\begin{array}{lll}1 & 1 & 0\end{array}\right)$ and (2 $\left.\begin{array}{lll}2 & 0 & 0\end{array}\right)$ reflections decrease gradually with increasing $\mathrm{TiO}_{2}$ loadings, implying that the unit cell dimensions and the order of the meso-structures will be affected by the incorporation of more $\mathrm{TiO}_{2},{ }^{35,36}$ as confirmed by the TEM images.

Wide-angle XRD patterns are presented in Fig. 2B. SBA-15 shows diffraction patterns with a broad peak at $22.2^{\circ}$. All
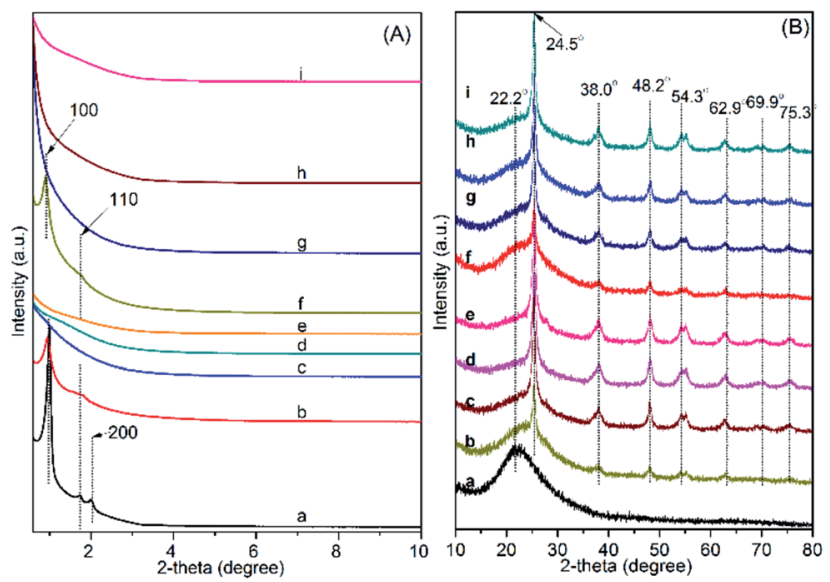

Fig. 2 Small-angle $(A)$ and wide-angle (B) XRD spectra of the samples: (a) SBA-15; (b)-(e) 10, 20, 30, 40\% $\mathrm{TiO}_{2} / \mathrm{SiO}_{2}$, (f)-(i) DCQ-10, 20, 30, $40 \% \mathrm{TiO}_{2} / \mathrm{SiO}_{2}$. patterns of $\mathrm{TiO}_{2} / \mathrm{SiO}_{2}$ and DCQ- $\mathrm{TiO}_{2} / \mathrm{SiO}_{2}$ samples show peaks at $2 \theta=24.5^{\circ}, 38.0^{\circ}, 48.2^{\circ}, 54.3^{\circ}, 62.9^{\circ}, 69.9^{\circ}$, and $75.3^{\circ}$ (JCPDSICDD no. 21-1272), which are assigned to the anatase reflections

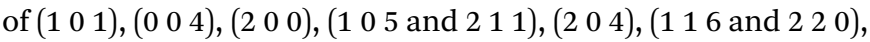
and (2 115 ), respectively. ${ }^{28}$ Intensities of these peaks increase markedly with increasing $\mathrm{TiO}_{2}$ loadings. No peak for the $\left(\begin{array}{lll}1 & 1 & 0\end{array}\right)$ rutile reflection at $27.4^{\circ}$ has been detected in the patterns of all samples. These results indicate that $\mathrm{TiO}_{2}$ in the samples is pure anatase with no secondary crystal phases of either brookite or rutile. It was reported that anatase in pure $\mathrm{TiO}_{2}$ would transform to rutile when the calcination temperature was higher than $400{ }^{\circ} \mathrm{C} .{ }^{37}$ In this study, no rutile phase is observed although all samples are calcined at $550{ }^{\circ} \mathrm{C}$. It could be attributed to the stabilizing effect of SBA-15 that enhanced the thermal stability of the anatase crystalline phase.

\subsection{Raman spectroscopy}

Raman spectra of all samples are shown in Fig. 3. Peaks at 149, 401,519 , and $645 \mathrm{~cm}^{-1}$ can be found in the spectra of all samples, except for DCQ. These peaks are assigned to the $\mathrm{E}_{\mathrm{g}(1)}$, $\mathrm{B}_{1 \mathrm{~g}(1)}, \mathrm{A}_{1 \mathrm{~g}}$ (or $\mathrm{B}_{1 \mathrm{~g}(2)}$ ), and $\mathrm{E}_{\mathrm{g}(3)}$ modes, respectively. Meanwhile, there are no bands at 268 and $601 \mathrm{~cm}^{-1}$, which correspond to the $\mathrm{TiO}_{2}$ rutile phase. ${ }^{28,38,39}$ This observation is consistent with the above XRD results, indicating clearly that only the anatase phase of $\mathrm{TiO}_{2}$ is present in these samples. Furthermore, the intensities of these four peaks increase with increasing $\mathrm{TiO}_{2}$ loadings. Other peaks at 291, 1199, 1229, 1311, 1571, 1595, and $1650 \mathrm{~cm}^{-1}$ in Fig. $3 \mathrm{f}-\mathrm{j}$ is regarded as characteristic bands of DCQ. ${ }^{40}$ In particular, bands at 1311,1571 , and $1650 \mathrm{~cm}^{-1}$ can be assigned to the coupled ring vibration, aromatic vibration, and CO stretching vibration of the quinacridone groups in DCQ.

\subsection{TEM}

Some TEM images of SBA-15 and DCQ- $X \% \mathrm{TiO}_{2} / \mathrm{SiO}_{2}$ samples are selected and shown in Fig. 4. Other images are presented in the ESI (Fig. S1-S9†). The long-range ordering and hexagonally arranged pores of SBA-15 can be well recognized in Fig. 4A. The regular morphology is maintained in the samples of DCQ-10\%

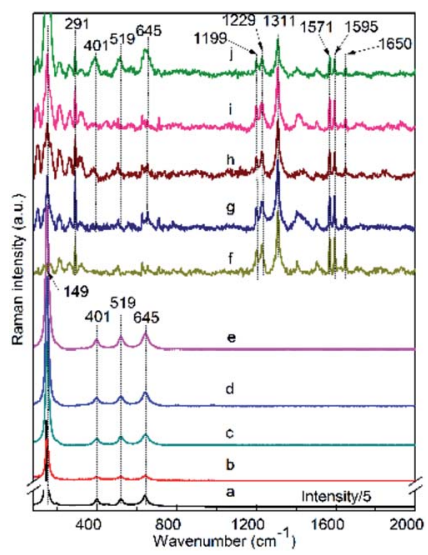

Fig. 3 Raman spectra of the photocatalysts: (a) $\mathrm{TiO}_{2}$; (b)-(e) 10, 20, 30, 40\% $\mathrm{TiO}_{2} / \mathrm{SiO}_{2}$; (f) DCQ; (g) -(j) DCQ-10, 20, 30, 40\% $\mathrm{TiO}_{2} / \mathrm{SiO}_{2}$. 

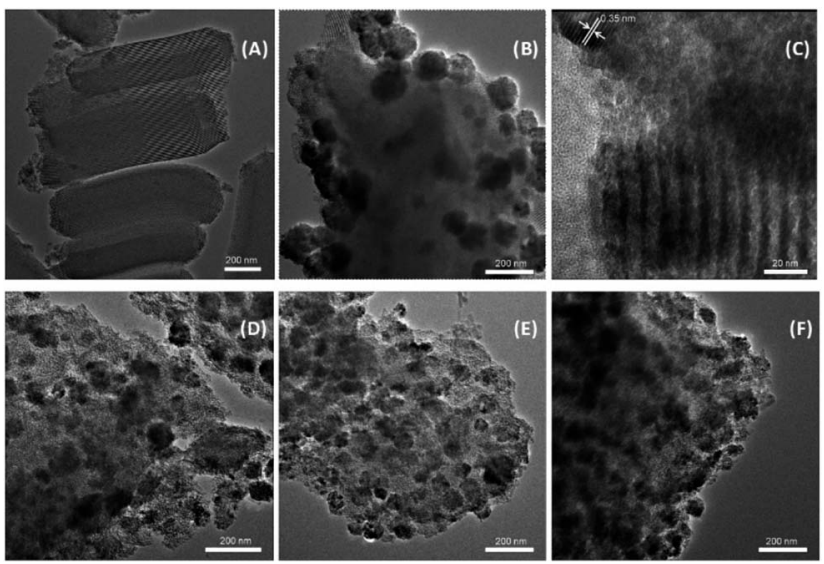

Fig. 4 TEM images of (A) SBA-15 and (B-F) DCQ-X\% TiO $2 / \mathrm{SiO}_{2}$ samples: $(B, C) X=10$, (D) $X=20$, (E) $X=30$, and (F) $X=40$.

$\mathrm{TiO}_{2} / \mathrm{SiO}_{2}$ (Fig. 4B). The symmetry of local structure gradually decreases with increasing $\mathrm{TiO}_{2}$ contents (Fig. 4D-F). Fig. $4 \mathrm{C}$ also confirms the anatase crystal structure of $\mathrm{TiO}_{2}$ particles. The lattice spacing $(d)$ is $\sim 0.35 \mathrm{~nm}$ between adjacent lattice planes. This matches well the distance between the $\left(\begin{array}{lll}1 & 0 & 1\end{array}\right)$ crystal planes of anatase $\mathrm{TiO}_{2}{ }^{23}$ The anatase phase of $\mathrm{TiO}_{2}$ shows generally strong photocatalytic behaviour in various reactions, for example, the decomposition of methylene blue in aqueous solutions. ${ }^{28}$ Hence, good photocatalytic performance is expected with the presence of anatase $\mathrm{TiO}_{2}$ in the samples presented in this work.

\section{$3.5 \quad$ FT-IR}

FT-IR spectra of the samples SBA-15, $X \% \mathrm{TiO}_{2} / \mathrm{SiO}_{2}$, and DCQ$X \% \mathrm{TiO}_{2} / \mathrm{SiO}_{2}$ and their corresponding assignments are shown in Fig. 5 and Table S2. $\uparrow$ The peak intensities of all $X \% \mathrm{TiO}_{2} / \mathrm{SiO}_{2}$ and DCQ- $X \% \mathrm{TiO}_{2} / \mathrm{SiO}_{2}$ samples at $960 \mathrm{~cm}^{-1}$ are obviously higher than that of SBA-15. It was reported that the incorporation of $\mathrm{TiO}_{2}$ into the framework of SBA-15 usually enhanced the intensity of the silanol shoulder (at $960 \mathrm{~cm}^{-1}$ ) of the $\nu_{\text {as }}(\mathrm{Si}-\mathrm{O}-$ $\mathrm{Si}$ ) band; ${ }^{36}$ such enhancement of the peak intensity is also a strong evidence about the formation of $\mathrm{Ti}-\mathrm{O}-\mathrm{Si}$ bonds in all

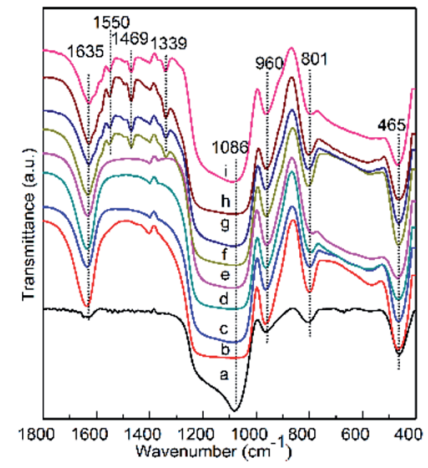

Fig. 5 FT-IR spectra of the samples: (a) SBA-15; (b)-(e) 10, 20, 30, 40\% $\mathrm{TiO}_{2} / \mathrm{SiO}_{2}$, (f)-(i) DCQ-10, 20, 30, 40\% $\mathrm{TiO}_{2} / \mathrm{SiO}_{2}$.
Table 1 Elemental analysis of SBA-15 and DCQ-X\% $\mathrm{TiO}_{2} / \mathrm{SiO}_{2}$

\begin{tabular}{|c|c|c|c|c|}
\hline Samples & $\begin{array}{l}\text { C } \\
(w t \%)\end{array}$ & $\begin{array}{l}\mathrm{N} \\
\text { (wt\%) }\end{array}$ & $\begin{array}{l}\mathrm{H} \\
(\mathrm{wt} \%)\end{array}$ & $\begin{array}{l}\text { DCQ loading } \\
(\mathrm{wt} \%)\end{array}$ \\
\hline SBA-15 & 0.525 & 0.150 & 0.976 & - \\
\hline DCQ-10\% $\mathrm{TiO}_{2} / \mathrm{SiO}_{2}$ & 1.327 & 0.379 & 2.411 & 3.12 \\
\hline DCQ-20\% $\mathrm{TiO}_{2} / \mathrm{SiO}_{2}$ & 2.225 & 0.477 & 1.765 & 4.45 \\
\hline DCQ-30\% $\mathrm{TiO}_{2} / \mathrm{SiO}_{2}$ & 2.426 & 0.513 & 2.062 & 4.94 \\
\hline DCQ-40\% $\mathrm{TiO}_{2} / \mathrm{SiO}_{2}$ & 1.893 & 0.476 & 2.129 & 4.44 \\
\hline
\end{tabular}

$X \% \mathrm{TiO}_{2} / \mathrm{SiO}_{2}$ and DCQ- $X \% \mathrm{TiO}_{2} / \mathrm{SiO}_{2}$ samples. At the same time, bands at 1550, 1469, and $1339 \mathrm{~cm}^{-1}$, which are characteristic of DCQ (Table S2 $\dagger$ ), can only be found in spectra of DCQ$X \% \mathrm{TiO}_{2} / \mathrm{SiO}_{2}$.

\subsection{Elemental analysis and UV-vis DRS}

In order to investigate the loadings of DCQ in the samples of DCQ- $X \% \mathrm{TiO}_{2} / \mathrm{SiO}_{2}$, elemental analysis is performed and the results are shown in Table 1 . The DCQ loadings in the samples range from about 3 to $5 \mathrm{wt} \%$, the sequences are ranked in the following order: DCQ-30\% $\mathrm{TiO}_{2} / \mathrm{SiO}_{2}>\mathrm{DCQ}-20 \% \mathrm{TiO}_{2} / \mathrm{SiO}_{2}>$ DCQ- $40 \% \mathrm{TiO}_{2} / \mathrm{SiO}_{2}>$ DCQ- $10 \% \mathrm{TiO}_{2} / \mathrm{SiO}_{2}$.

Fig. 6 presents the UV-vis diffuse reflectance spectra of SBA15, $\mathrm{TiO}_{2}, \mathrm{DCQ}$, and $X \% \mathrm{TiO}_{2} / \mathrm{SiO}_{2}$ and DCQ- $X \% \mathrm{TiO}_{2} / \mathrm{SiO}_{2}$. As shown in Fig. 6A, all samples show high absorbance in the ultraviolet region (200-400 $\mathrm{nm}$ ) except for $\mathrm{SBA}-15$. $\mathrm{TiO}_{2}$ has an adsorption edge at $376 \mathrm{~nm}$. This is consistent with the value of anatase $\mathrm{TiO}_{2}$ reported in the literature. ${ }^{\mathbf{4 1 , 4 2}}$ The adsorption edge of $X \% \mathrm{TiO}_{2} / \mathrm{SiO}_{2}$ samples are slightly red shifted from $376 \mathrm{~nm}$ to $391 \mathrm{~nm}$ with increasing $\mathrm{TiO}_{2}$ contents. The red shift might be caused by the formation of Ti-O-Si chemical bonds ${ }^{\mathbf{4 1 , 4 3}}$ during the in situ incorporation of $\mathrm{TiO}_{2}$. The absorption intensities of $X \% \mathrm{TiO}_{2} / \mathrm{SiO}_{2}$ samples in the ultraviolet region are also found to be increased with increasing amounts of $\mathrm{TiO}_{2}$ incorporated. It can be observed from Fig. 6B that all DCQ- $X \% \mathrm{TiO}_{2} / \mathrm{SiO}_{2}$ samples show broad and prominent absorbance in the visible light region of 450-600 $\mathrm{nm}$. Obviously, this is the result of the sensitization of DCQ, which can further facilitate a more efficient utilization of simulated sunlight and improve the photocatalytic activity under full spectrum irradiation. It can also be seen the absorbance intensity of DCQ- $X \% \mathrm{TiO}_{2} / \mathrm{SiO}_{2}$ in the
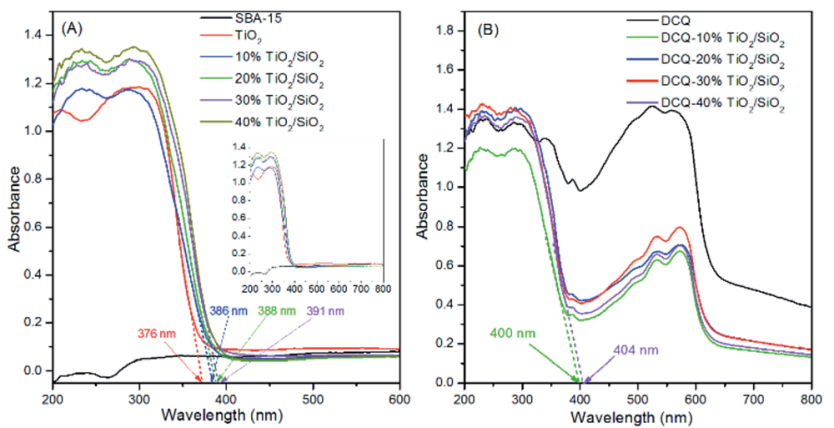

Fig. 6 UV-vis DRS of (A) SBA-15, $\mathrm{TiO}_{2}, X \% \mathrm{TiO}_{2} / \mathrm{SiO}_{2}$ and (B) $\mathrm{DCQ}$, $\mathrm{DCQ}-X \% \mathrm{TiO}_{2} / \mathrm{SiO}_{2}(X=10,20,30,40)$. 
region of 450-600 $\mathrm{nm}$ is consistent with the DCQ loadings in all the samples (Table 1$)$. The band gap energies $\left(E_{\mathrm{g}}\right)$ of the samples can be estimated according to the empirical eqn $(2)^{\mathbf{4 2 , 4 4}}$ and the results are shown in Table $\mathrm{S} 3 . \dagger$

$$
E_{\mathrm{g}}=1240 / \lambda_{\mathrm{g}}
$$

where $E_{\mathrm{g}}$ is the energy gap and $\lambda_{\mathrm{g}}$ is absorption threshold. Table $\mathrm{S} 3 \dagger$ shows that the incorporation of $\mathrm{TiO}_{2}$ into SBA-15 and the sensitization of the samples with DCQ can get the band gap of $\mathrm{TiO}_{2}$ narrowed, although the effect is not significant.

\subsection{Photocatalytic degradation}

The photocatalytic degradation efficiency $(D \%)$ of imidazolium ionic liquids were tested and shown in Fig. 7. It can be seen that $D \%$ of [BMIM] Br within $180 \mathrm{~min}$ is only 10 with SBA-15 in the blank experiment. $D \%$ of [BMIM] Br can reach about 65 to 75 with un-sensitized $X \% \mathrm{TiO}_{2} / \mathrm{SiO}_{2}$ catalysts under simulated sunlight irradiation. This indicates that $\mathrm{TiO}_{2}$ incorporated into the composites acts as photocatalytic active site and plays an important role on the photodegradation. It is well known that the irradiation (especially the UV irradiation according to DRS results) on the active sites of $\mathrm{TiO}_{2}$ will generate conduction-band electrons $\left(\mathrm{e}^{-}\right)$and valence band holes $\left(\mathrm{h}^{+}\right)$, which react with $\mathrm{H}_{2} \mathrm{O}_{2}$ to produce ${ }^{\circ} \mathrm{OH}$ radicals. Both valence band holes and ${ }^{\circ} \mathrm{OH}$ radicals are highly oxidative and can degrade organic compounds quickly. ${ }^{17,45}$

It is interesting to notice that the photodegradation performance is considerably improved when DCQ- $X \% \mathrm{TiO}_{2} / \mathrm{SiO}_{2}$ is used as catalysts under simulated sunlight irradiation, $D \%$ of [BMIM] Br could reach 90-95 within $180 \mathrm{~min}$. This can be explained by the sensitization of $\mathrm{TiO}_{2} / \mathrm{SiO}_{2}$ with DCQ, which can significantly enhance the utilization of solar light and then improve the photodegradation efficiency. According to the results of UV-vis DRS, the enhancement and promotion is

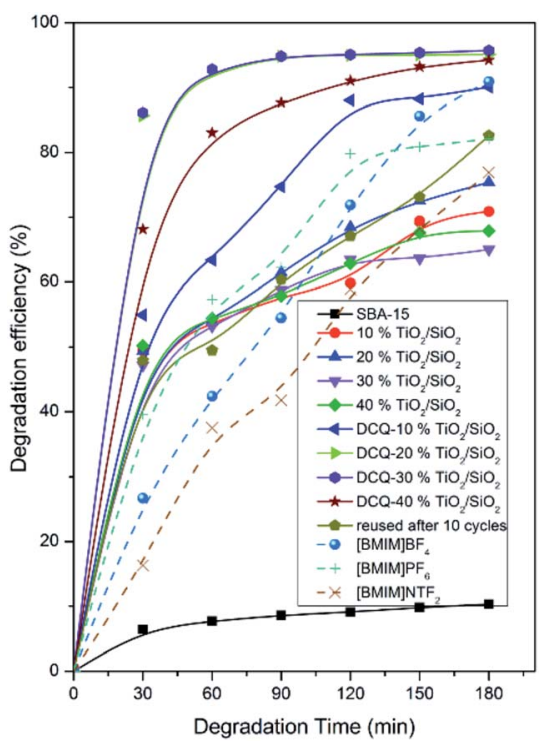

Fig. 7 Degradation efficiency of imidazolium ILs under simulated sunlight irradiation. Solid line: the photodegradation target was [BMIM] $\mathrm{Br}$; dash line: $\mathrm{DCQ}-30 \% \mathrm{TiO}_{2} / \mathrm{SiO}_{2}$ was used as the photocatalyst. presumably due to the strong absorption of DCQ- $X \% \mathrm{TiO}_{2} / \mathrm{SiO}_{2}$ samples in the visible-light region, rather than the band gap narrowing of $\mathrm{TiO}_{2}$. The similar result was also reported by Sun et $a .^{41}$ when $\mathrm{N}-\mathrm{Ag}-\mathrm{TiO}_{2}$ catalyst was applied in photocatalytic oxidation of phenol solution under visible light irradiation. It can be seen from Fig. 7 that $D \%$ of [BMIM]Br remains above 80 even after 10 recycling use, which means the photocatalyst has satisfactory stability under simulated sunlight irradiation. Further, three other ILs were adopted to investigate the effect of water solubility on $D \%$. It shows that the worse the water solubility, the lower the degradation efficiency, but $D \%$ of $[\mathrm{BMIM}] \mathrm{NTF}_{2}$ can still reach up to nearly 77 within $180 \mathrm{~min}$.

LC/MS was used to identify the intermediates of [BMIM] cation in the photocatalytic degradation process. Main peaks in the HPLC chromatograms (Fig. S10A $\dagger$ ) are located at retention times of 2.6, 2.8, 2.9, and $3.4 \mathrm{~min}$, which can be assigned to [BMIM] ${ }^{+}$ and its photodegradation intermediates (a-c, Fig. S10B-D $†$ ). The peak of $[\mathrm{BMIM}]^{+}$disappears rapidly during degradation; meanwhile, the peak intensity of intermediate (a) increases from 30 to $60 \mathrm{~min}$ and then decreases from 60 to $180 \mathrm{~min}$. These trends indicate that intermediate (a) is produced first during the degradation reaction and is then degraded continuously in the photocatalytic process. While peak intensities of intermediates (b) and (c) gradually increase from 30 to $180 \mathrm{~min}$. Based on the above analysis, the mechanism of $[\mathrm{BMIM}]^{+}$photocatalytic degradation is proposed in Scheme $\mathrm{S} 1 \dagger$ and can be presented as follows: $[\mathrm{BMIM}]^{+}$is firstly oxidized to 1-butyl-3-methylimidazolidine-2,4,5trione (a), and then degraded to 2-oxo-2-ureidoacetic acid (b) and butyric acid (c) by ring-opening. And the compound of (b) and (c) will be finally mineralized to $\mathrm{CO}_{2}, \mathrm{H}_{2} \mathrm{O}$ etc.

\section{Conclusions}

In this study, the photocatalysts $\mathrm{TiO}_{2} / \mathrm{SiO}_{2}$ and DCQ-TiO $/ \mathrm{SiO}_{2}$ are prepared using in situ synthesis and dye sensitization. The results of TEM, XRD analysis, Raman spectroscopy, elemental analysis and UV-vis diffuse reflectance spectra clearly show the formation of $\mathrm{TiO}_{2}-\mathrm{SiO}_{2}$ mixed oxides in the $\mathrm{TiO}_{2} / \mathrm{SiO}_{2}$ and DCQ$\mathrm{TiO}_{2} / \mathrm{SiO}_{2}$ samples. $\mathrm{TiO}_{2}$ in the samples is pure anatase without secondary crystal phase of brookite or rutile. Results of Raman, FT-IR and UV-vis DRS also indicate that DCQ is successfully incorporated into $\mathrm{DCQ}-\mathrm{TiO}_{2} / \mathrm{SiO}_{2}$. The photocatalysts are then used in the degradation of imidazolium ionic liquids. The degradation experiments show that dye sensitization of $\mathrm{TiO}_{2} / \mathrm{SiO}_{2}$ with DCQ can enhance the photodegradation efficiency by over $20 \%$. Around $95 \%$ of [BMIM]Br can be degraded within $180 \mathrm{~min}$ with the use of DCQ-TiO ${ }_{2} / \mathrm{SBA}-15$ as photocatalyst under simulated sunlight irradiation. The dye-sensitized photocatalysts can thus be applied efficiently in the degradation of ILs, e.g. for treating spillage of ILs. The dye sensitized catalysts are expected to be applicable for the degradation of other contaminants in aquatic environments. Such applications are under investigation.

\section{Acknowledgements}

This study is performed with the financial support of the National Natural Science Foundation of China (Grant No. 
21006035 and 21676099), and the Fundamental Research Funds for the Central Universities, South China University of Technology.

\section{Notes and references}

1 W. Zhu, P. Wu, L. Yang, Y. Chang, Y. Chao, H. Li, Y. Jiang, W. Jiang and S. Xun, Chem. Eng. J., 2013, 229, 250-256.

2 Y. Yu, J. Mai, L. Huang, L. Wang and X. Li, RSC Adv., 2014, 4, 12756-12762.

3 Y. Yu, J. Mai, L. Wang, X. Li, Z. Jiang and F. Wang, Sci. Rep., 2014, 4, 5997.

4 J. Neumann, C. Cho, S. Steudte, J. Koser, M. Uerdingen, J. Thoming and S. Stolte, Green Chem., 2012, 14, 410-418.

5 J. Ma, L. Cai, B. Zhang, L. Hu, X. Li and J. Wang, Ecotoxicol. Environ. Saf., 2010, 73, 1465-1469.

6 J. McFarlane, W. Ridenour, H. Luo, R. Hunt, D. DePaoli and R. Ren, Sep. Sci. Technol., 2005, 40, 1245-1265.

7 T. Thuy Pham, C. Cho and Y. Yun, Water Res., 2010, 44, 352372.

8 K. Docherty and J. Kulpa, Green Chem., 2005, 7, 185-189.

9 M. Matzke, S. Stolte, K. Thiele, T. Juffernholz, J. Arning, J. Ranke, U. Biermann and B. Jastorff, Green Chem., 2007, 9, 1198-1207.

10 C. Pretti, C. Chiappe, D. Pieraccini, M. Gregori, F. Abramo, G. Monni and L. Intorre, Green Chem., 2006, 8, 238-240.

11 J. Ranke, A. Müller, U. Weber, F. Stock, S. Stolte, J. Arning, R. Störmann and B. Jastorff, Ecotoxicol. Environ. Saf., 2007, 67, 430-438.

12 P. Stepnowski, A. Skladanowski and A. Ludwiczak, Hum. Exp. Toxicol., 2004, 23, 513-517.

13 H. Zhou, Y. Shen, P. Lv, J. Wang and J. Fan, Sep. Purif. Technol., 2013, 104, 208-213.

14 E. Siedlecka, S. Stolte, M. Gołębiowski, A. Nienstedt, P. Stepnowski and J. Thöming, Sep. Purif. Technol., 2012, 101, 26-33.

15 E. Siedlecka, M. Gołębiowski, Z. Kaczyński, J. Czupryniak, T. Ossowski and P. Stepnowski, Appl. Catal., B, 2009, 91, 573-579.

16 E. Siedlecka, W. Mrozik, Z. Kaczynski and P. Stepnowski, J. Hazard. Mater., 2008, 154, 893-900.

17 P. Stepnowski and A. Zaleska, J. Photochem. Photobiol., A, 2005, 170, 45-50.

18 A. Morawski, M. Janus, I. Goc-Maciejewska, A. Syguda and J. Pernak, Pol. J. Chem., 2005, 79, 1929-1935.

19 R. Katoh and K. Takahashi, Radiat. Phys. Chem., 2009, 78, 1126-1128.

20 X. Li, J. Zhao, Q. Li, L. Wang and S. Tsang, Dalton Trans., 2007, 1875-1880.

21 E. Bosse, L. Berthon, N. Zorz, J. Monget, C. Berthon, I. Bisel, S. Legand and P. Moisy, Dalton Trans., 2008, 924-931.

22 G. Le Rouzo, C. Lamouroux, V. Dauvois, A. Dannoux, S. Legand, D. Durand, P. Moisy and G. Moutiers, Dalton Trans., 2009, 6175-6184.
23 J. Schneider, M. Matsuoka, M. Takeuchi, J. Zhang, Y. Horiuchi and D. Bahnemann, Chem. Rev., 2014, 114(19), 9919-9986.

24 J. Chao, Z. Xie, X. Duan, Y. Dong, Z. Wang, J. Xu, B. Liang, B. Shan, J. Ye, D. Chen and G. Shen, CrystEngComm, 2012, 14, 3163-3168.

25 J. Yu, W. Ho, J. Yu, H. Yip, P. Wong and J. Zhao, Environ. Sci. Technol., 2005, 39, 1175-1179.

26 J. Di, S. Li, Z. Zhao, Y. Huang, Y. Jia and H. Zheng, Chem. Eng. J., 2015, 281, 60-68.

27 J. Yang, J. Zhang, L. Zhu, S. Chen, Y. Zhang, Y. Tang, Y. Zhu and Y. Li, J. Hazard. Mater., 2006, 137, 952-958.

28 Y. Acosta-Silva, R. Nava, V. Hernández-Morales, S. MacíasSánchez, M. Gómez-Herrera and B. Pawelec, Appl. Catal., B, 2011, 110, 108-117.

29 M. Tototzintle, I. Oller, A. Ramírez, S. Malato and M. Maldonado, Chem. Eng. J., 2015, 273, 205-213.

30 C. Shen, Y. Wang, J. Xu and G. Luo, Chem. Eng. J., 2015, 277, 48-55.

31 G. Li and X. Zhao, Ind. Eng. Chem. Res., 2006, 45(10), 35693573.

32 G. Wittmann, K. Demeestere, A. Dombi, J. Dewulf and H. Van Langenhove, Appl. Catal., B, 2005, 61, 47-57.

33 W. Yue, C. Randorn, P. S. Attidekou, Z. Su, J. T. S. Irvine and W. Zhou, Adv. Funct. Mater., 2009, 19, 2826-2833.

34 W. Jung, S. Baek, J. Yang, K. Lim, M. Lee, G. Lee, S. Park and S. Hong, Catal. Today, 2008, 131, 437-443.

35 M. Mazaj, W. Stevens, N. Logar, A. Ristić, N. Tušar, I. Arčon, N. Daneu, V. Meynen, P. Cool, E. Vansant and V. Kaučič, Microporous Mesoporous Mater., 2009, 117, 458-465.

36 S. Das, M. Bhunia and A. Bhaumik, J. Solid State Chem., 2010, 183, 1326-1333.

37 H. Yang, H. Lin, Y. Chien, J. Wu and H. Wu, Catal. Lett., 2009, 131, 381-387.

38 R. Zukerman, L. Vradman, L. Titelman, L. Zeiri, N. Perkas, A. Gedanken, M. Landau and M. Herskowitz, Mater. Chem. Phys., 2010, 122, 53-59.

39 M. Alvaro, C. Aprile, M. Benitez, E. Carbonell and H. García, J. Phys. Chem. B, 2006, 110, 6661-6665.

40 F. Schulte, K. Brzezinka, K. Lutzenberger, H. Stege and U. Panne, J. Raman Spectrosc., 2008, 39, 1455-1463.

41 H. Sun, G. Zhou, S. Liu, H. Ang, M. Tadé and S. Wang, Chem. Eng. J., 2013, 231, 18-25.

42 A. Police, S. Basavaraju, D. Valluri, V. Muthukonda, S. Machiraju and J. Lee, Chem. Eng. J., 2014, 247, 152-160.

43 J. Li, S. Zhou, G. Hong and C. Chang, Chem. Eng. J., 2013, 219, 486-491.

44 J. Xu, K. Li, W. Shi, R. Li and T. Peng, J. Power Sources, 2014, 260, 233-242.

45 P. Wang, T. Zhou, R. Wang and T. Lim, Water Res., 2011, 45, 5015-5026. 